\title{
Molecular Detection of Infectious Bursal Disease Virus in Broiler Chickens of Diyala Province, Iraq
}

\author{
Amer Khazaal AL-Azzawi, Ammar Taleb Nasser, and Karim Sadun Al-Ajeeli \\ Department of Microbiology, College of Veterinary Medicine, University of Diyala, Iraq \\ *Corresponding author's Email: amer_alazawy@yahoo.com; ORCID: 0000- 0002-4422-5442
}

Received: 09 October 2021

Accepted: 24 November 2021

\begin{abstract}
Many broiler chickens farms in Diyala Province, Iraq, have shown clinical signs of infectious bursal disease virus (IBDV) in broiler chickens, including depression of birds, petechial hemorrhage in muscles of the thigh, and swollen bursa. Therefore, in the current study, necropsy samples (liver, spleen, bursa, and kidney) were collected from the mentioned broiler chickens. The samples were then subjected to conventional RT-PCR using specific primers to the VP2 gene. The results showed that five out of seven collected samples were positive to IBDV, and the RT-PCR produced a fragment of $260 \mathrm{bp}$. Furthermore, four tissue bursa samples were sent to AniCon Labor GmbH- Germany by using (FTA- card including four spots) for detection of IBDV by real-time RT-PCR using VP1 and VP2 genes to distinguish the pathogenic virulent strain of IBDV from non-virulent IBDV strains and to make the phylogenetic tree. Results showed that duplex RT-PCR generated a fragment of 690bp for VP1 gene and 700bp for VP2 genes of detected IBDV. Two out of 4 samples from suspected flocks were found positive with prevalence results of $50 \%$ for intermediated and non-virulent IBDV strains (IBDV nvv), and 50\% (2 samples) were very virulent (vvIBDV). The threshold Cycle $(\mathrm{Ct})$ value for RT-PCR for two isolates on bursa tissue ranged from 16.6 to 25.7. One strain was recorded in NCBI with the accession number of (MW8883071). Phylogenetic analysis of detected and sequenced IBDV indicated that the local studied virus was closely related to 710- Jordan isolate (accession number MF142560.1) and to the isolate 267-Jordan (MF 142517.1) with a higher identity reach of (99.2\%).
\end{abstract}

Keywords: Broiler chickens, Infectious bursal disease virus, RT-PCR

\section{INTRODUCTION}

Infectious bursal disease (IBD) is caused by a virus belonging to the Avibirnavirus genus of an RNA family Birnaviridae (Fauquet and Mayo, 2001). The disease occurred in the flock of broilers in Sussex, USA for the first time. It was also named (Gumboro) due to an outbreak of the disease recorded in Gumboro, Delaware, USA. Infected broiler chickens with the virus showed swollen bursa and destruction of bursal lymphocytes that resulted in severe immunosuppression of the defense system, and a high level of depression with trembling prostration. Furthermore, the infected birds showed white watery discharge and accumulation of urate in kidneys and urinary tubules with high mortality rates in acute disease conditions. Subclinical disease conditions were observed in birds less than three weeks of age, whereas the muscles of infected birds showed dehydration especially in those above three weeks of age (Saif and Barnes, 2003; HairBejo et al., 2004; Ingraor et al., 2013). Many IBD outbreaks occurred from 1987 to 1988 due to the emergence of virulent IBDV as a new serotype different from that of classic IBD in Europe. It was reported that the new serotype can cause the disease condition regardless of the high titer maternal antibodies, and this serotype was associated with severe clinical signs and high morbidity and mortality among infected chickens (OIE, 2018). Iraq is endemic with IBD, and the disease was firstly reported by Al-Sheikhly et al. (1978). Since its first observation, IBD has widely spread among poultry farms in Iraq. There are two serotypes of IBDV, (serotype 1 and serotype 2), the former is the main serotype responsible for classical IBD in poultry causing the known clinical signs in infected chickens and is used in vaccine preparation against IBD (Lukert and Saif, 2003; Mwenda et al., 2018). Serotype 2 did not induce similar clinical signs in specific pathogenfree (SPF) chickens induced by serotype 1 and induce neither protection against serotype 1 if used as a vaccine, nor pathological changes in the bursa of Fabricious and not causing a mortality rate experimentally in SPF chickens (van den Berg, 2000; van den Berg et al., 2004; 
Shehata et al., 2017). Furthermore, antibodies were detected in chickens and turkeys infected with IBDV serotype 2 but without clinical signs (Lukert and Saif, 2003). Subclinical infection of chicken with IBDV has great effects on BF and is associated with immunosuppression due to severe depletion of lymphocytes (Sharma et al., 2000). Accordingly, subclinical infection interrupted the estimation of the real distribution of IBDV among poultry farms worldwide. Therefore, the current study aimed to investigate the molecular evidence of IBDV in selected farms of broiler chickens in Diyala Governorate, Iraq

\section{MATERIALS AND METHODS}

The place of the current study was the virology and molecular biology laboratories of the College of Veterinary Medicine, University of Diyala, Iraq from September 2019 to June 2020.

\section{Ethical approval}

The Scientific ethical committee at the University of Diyala/ College of Veterinary Medicine, Iraq, approved the research and confirmed the ethical number Vet 201 Medicine August 2019 A, A and K for the current study.

\section{Molecular detection of infectious bursal disease virus}

Molecular detection of IBDV was followed using reverse transcriptase RT-PCR and real-time PCR. Accordingly, tissue samples were collected from the (liver, spleen, bursa, and kidney) of broiler chickens that showed severe IBDV infections at necropsy findings (Figure 1) at age of 2-3 weeks. The samples were in sterile plastic test tubes and stored in a deep freezer at $\left(-20^{\circ} \mathrm{C}\right)$ until used. Viral RNA was extracted from tissue samples of the spleen, liver, and bursa using of Trizole reagent (Invitrogen, USA) according to the manufacturer's instruction. The following RT-PCR condition was used to amplify the IBDV VIP2 gene in a single-tube assay with a final reaction of $25 \mu 1$ using the commercially available kit (Promega, USA) was used for RT- PCR assays. Oligonucleotide primers used in the detection of IBDV (Microgen, Korea) included IBDV-F (5CAGGTGGGGTAACAACAATCA-3) and IBDVR(5CGGCAGGTGGAACAATG-3) as previously described by Meir et al. (2001) to amplify a 260-bp region of the hypervariable sequence in the VP2 gene, by the use of Access RT-PCR System and RNasin ${ }^{\circledR}$ Ribonuclease Inhibitor kit (Promega ${ }^{\circledR}$, Madison, USA). The RT-PCR tubes were quickly spun for a few seconds and were transferred to a programmable thermal cycler (Eppendorf, USA) using the following temperature profile for 40 cycles. The RT-PCR was conducted at RT reaction of $50^{\circ} \mathrm{C}$ for 10 minutes and was followed by 40 cycles of PCR at $95^{\circ} \mathrm{C}$ for 1 minute, annealing of $59^{\circ} \mathrm{C}$ for 40 seconds, an extension of $72^{\circ} \mathrm{C}$ for 1 minute, following the final extension of $72^{\circ} \mathrm{C}$ for 10 minutes. Additionally, four tissue samples from the Bursa of Fabricius were sent to AniCon Labor GmbH- Germany using FTA (card including 4 spots) for the detection of IBDV by real-time RT-PCR to distinguish the pathogenic virulent strain of IBDV from non-virulent IBDV strains and to make the phylogenetic tree. Real-Time-RT-PCR, (Kylt ${ }^{\circledR}$ IBDV Screening kits, Germany) was used for detection of viral RNA of (IBDV) from the tissue of the Bursa and spleen. The RNA target sequences for IBDV as well as for the endogenous control (beta-Actin) are reverse transcribed (RT) and amplified in parallel with respective primer pairs for VP1 and VP2 genes in PCR.
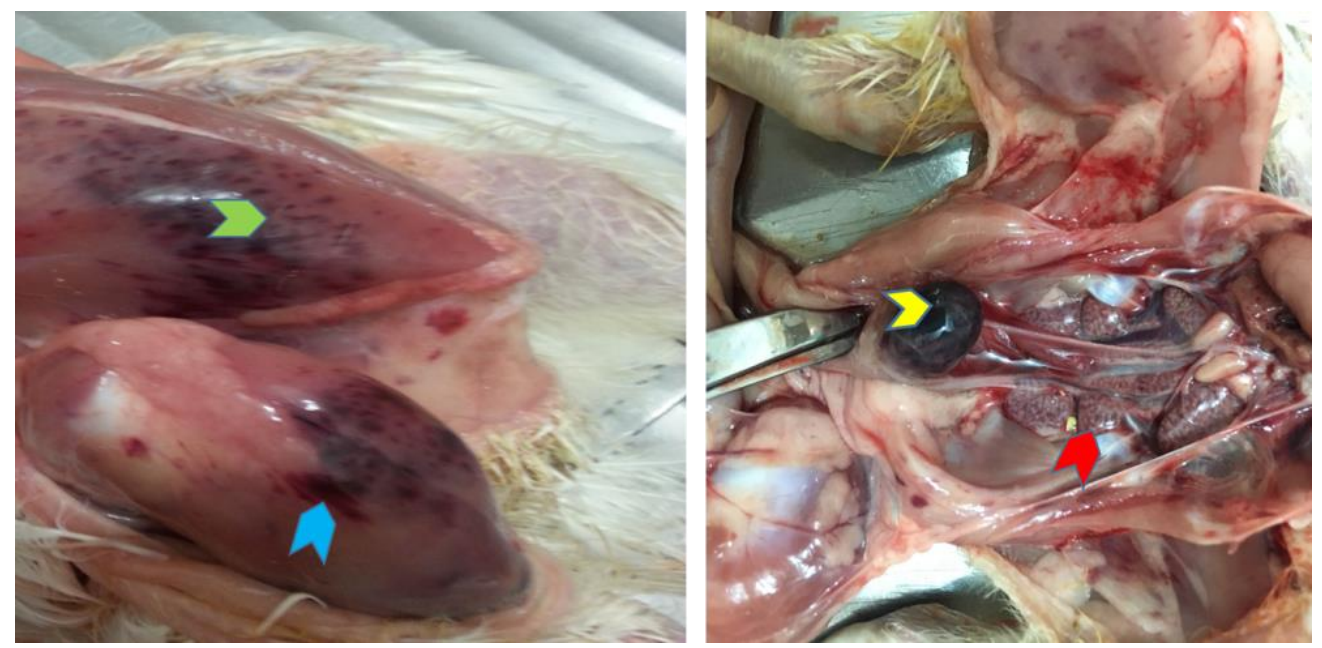

Figure 1. Necropsy examination of infected broiler chickens with infectious bursal disease virus. Ecchymotic hemorrhages on thigh and breast muscles (blue and green color), the presence of hemorrhages on the serosal surface of the Bursa (yellow color), and kidneys filled with urates (red color). 


\section{Sequence and phylogenetic analysis of infectious bursal disease virus}

The partial fragment sequence of the VP1 and VP2 gene of the segmented A and B of IBDV have been sequenced and were phylogenetically analyzed based on comparison with that of the corresponding 31 reference strains from NCBI. The partial sequence of IBDV local isolates with accession number (Diyala/VP2/MW883071) was aligned using Clustal $\mathrm{W}$ that was enclosed in MEGA.6 software. This sequence of local isolate and all other 31 corresponding reference IBDV strains from NCBI were compared.

\section{RESULTS}

\section{Molecular detection of infectious bursal disease virus}

Out of 7 samples, 5 samples $(71 \%)$ were positive for IBDV by using RT-PCR. Positive samples generated a specific DNA band of 260 bp as shown in (Figure 2).

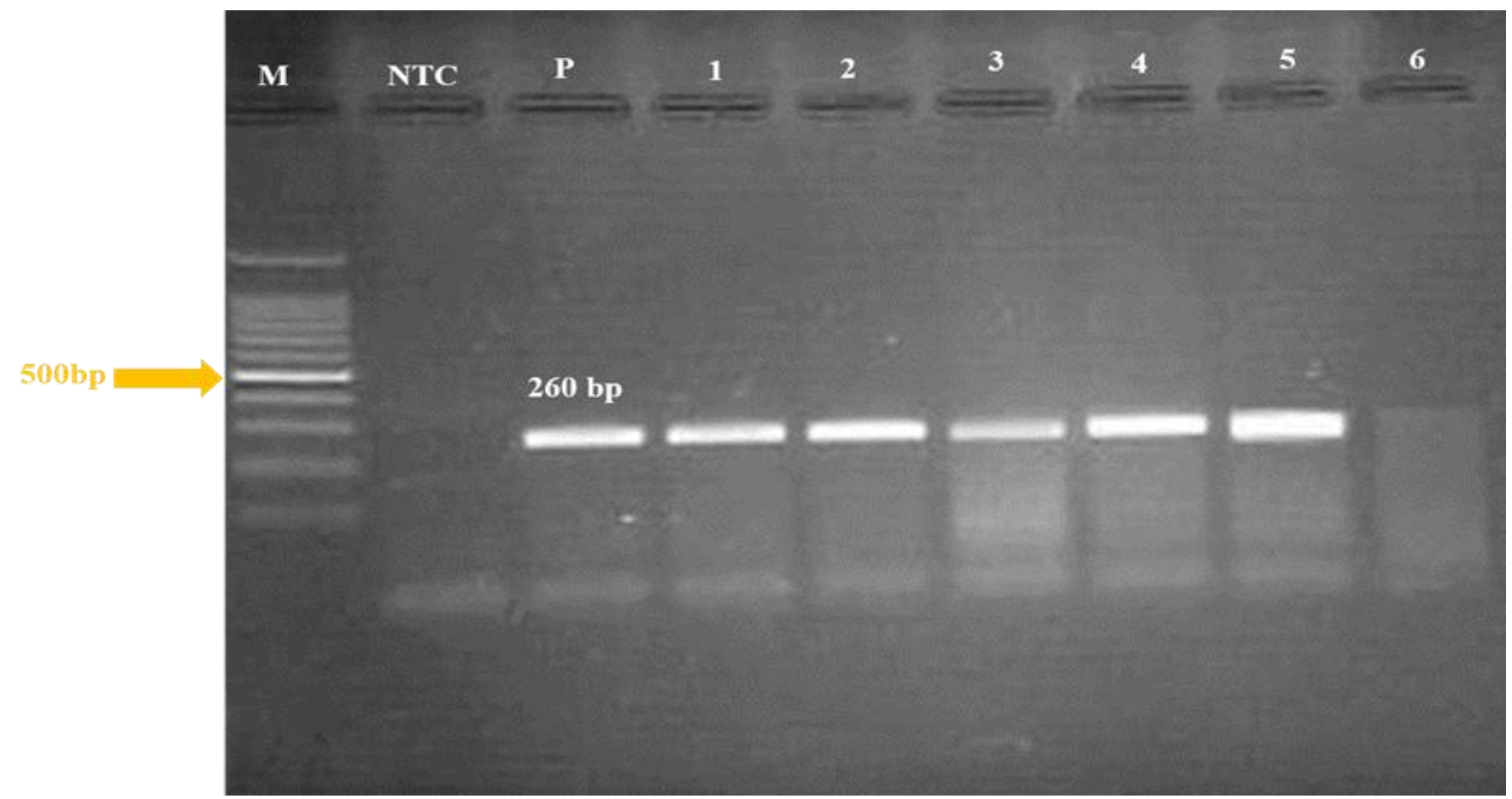

Figure. 2 Screening tissue samples of chickens infected with infectious bursal disease virus in (Baquba) using RT-PCR and Oligonucleotide primers (IBDV-F and IBDV-R) produced the target band of 260bp. The $1 \%$ agarose gel was electrophoresed and stained with ethidium bromide. Lane no. 1 to Lane 5 positive samples from chickens infected with IBDV. M: 100 marker; NTC: non-template control. P: Positive control (IBDV).

\section{Real-time RT-PCR for the detection of very virulent infectious bursal disease virus}

The results of four tissue samples of the bursa of Fabricius sent to AniCon Labor GmbH- company in Germany and analyzed by duplex Real-Time RT-PCR, indicated a $690 \mathrm{bp}$ fragment of the VP1 gene, and a $700 \mathrm{bp}$ fragment of the VP2 gene. These two fragments have been sequenced and phylogenetically analyzed based on comparison to the known vaccine and reference strains from NCBI. The RT-PCR results indicated that 2 out of 4 samples from suspected flocks were found positive with a prevalence results of $50 \%$ for intermediated and nonvirulent IBDV strains (IBDV nvv), and 50\% (2 samples) were very virulent (vvIBDV). The threshold cycle $(\mathrm{Ct})$ value for RT-PCR for two isolates on bursa tissue ranged from 16.6 to 25.7. One strain was recorded in NCBI and gained accession number of (MW883071).

After comparison with all reference strains the local sample isolates (Diyala/VP2/MW883071) was the one most related to the 710- Jordan isolate with accession number (MF142560.1) and to isolate 267-Jordan (MF $142517.1)$ with a higher identity reach to $(99.2 \%)$ for the VP2 gene and clusters with the group of very virulent IBDV strains. Moreover, the sample (Diyala/VP2/MW883071) exhibited $99.2 \%$ and $98.7 \%$ of VP2 gene to the reference strains of 710 Jorda (MF142485.1) and 267-Jordan (MF142466.1) respectively (Figure 3). 


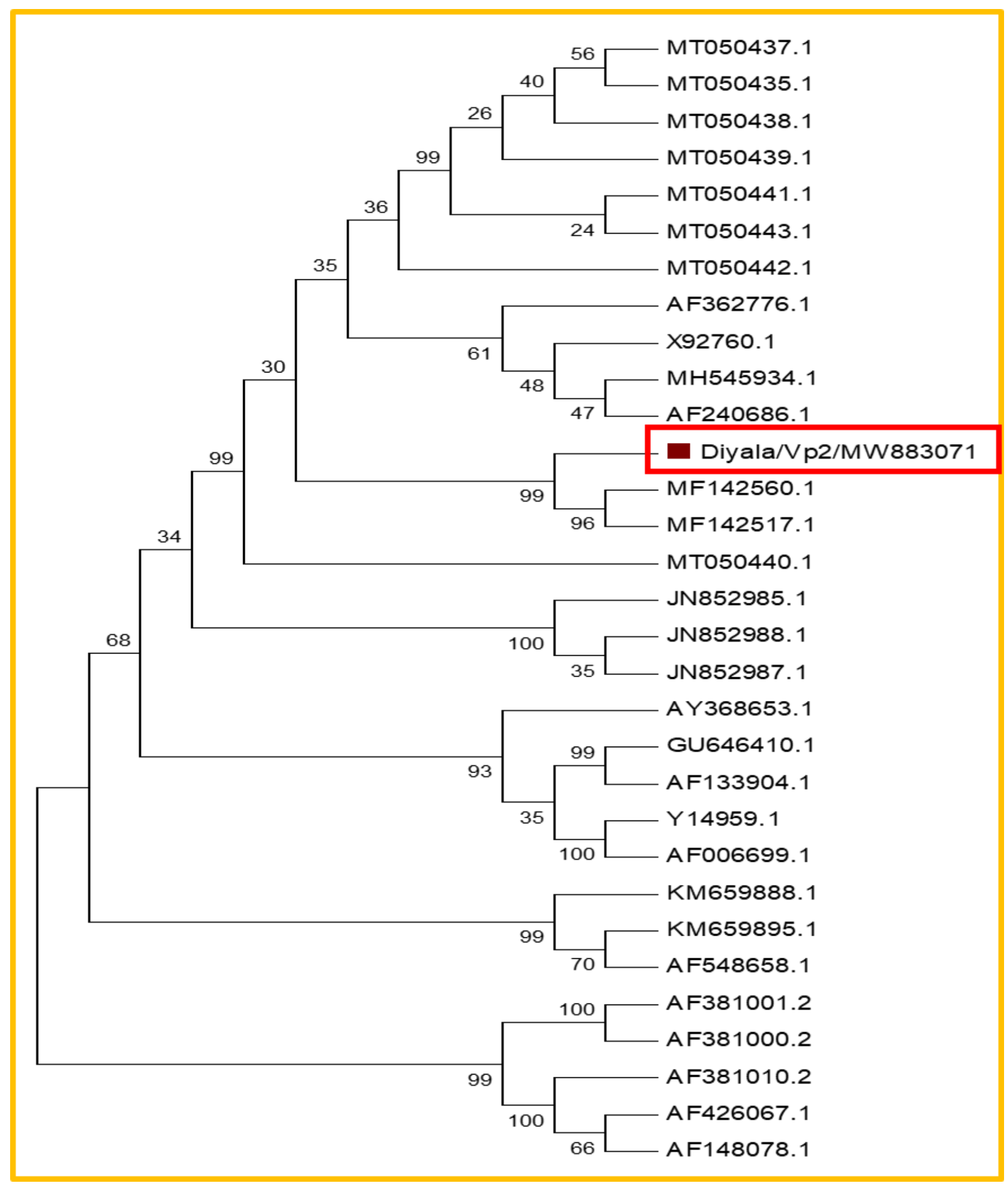

Figure 3. Phylogenetic relationships determined by the VP2 gene sequence of the local IBDV isolates and the corresponding sequence of infectious bursal disease virus from GenBank. The phylogenetic trees were generated using the treetop phylogenetic tree prediction program (GeneBee-Molecular Biology Server MGA-6). Diyala isolate was located in one glister with other isolates (MF142560.1) and (MF142517.1) from the USA. 


\section{DISCUSSION}

Chicken is the only avian species known to be susceptible to clinical disease and characteristic lesions caused by IBDV that appeared at 3 weeks of age and older (Muller et al., 2012). Whereas co-infection of chicken anemia virus (CAV) with IBDV increased the susceptibility as both viruses caused immunosuppression and lead to severe clinical signs in infected broilers and or layers. Furthermore, anemia, subcutaneous hemorrhage, and decreased resistance to secondary bacterial diseases such as gangrenous dermatitis might be noticed (Ali, 2001; Zanella et al., 2001; Schat and van Santen, 2013). Chickens of all ages are susceptible to CAV which is ubiquitous in the environment and highly resistant to heat and various chemical agents (McNulty et al., 1990). Maternal antibodies in broiler chickens prevent the subclinical signs due to infection with CAV syndrome but do not prevent the clinical infection, and the transmission of the virus occurred when maternal immunity was declined (Sommer, and Cardona, 2003).

\section{Detection of infectious bursal disease virus from tissue samples using RT-PCR}

In the present study, acute cases of IBD in vaccinated were diagnosed depending on clinical signs and gross lesions observed in postmortem findings especially in the Bursa of Fabricius. The findings of the current study showed that $71 \%$ of collected necropsy samples were positive for IBDV in RT-PCR, similar findings were reported by Mawgod et al. (2014). Who found that 20 from 52 field samples were positive of infectious bursal disease virus by using RT-PCR.

The rise of new strains of IBDV mostly was attributed to changes in VP2 gene. Accordingly, amplifying the hypervariable region of the VP2 gene of (260 bp amplicon) that contained the most informative genetic data regarding strain variability was of significant importance. Therefore, this amplicon was chosen for sequence analysis to characterize IBDV strains molecularly. Furthermore, this can help to point out the possibility of the presence of variations occurring naturally or experimentally through the attenuation of strains, which might lead to changes in the virulence of viruses or their antigenicity.

The current study showed high mortality in all broiler flocks despite the wide use of vaccines. The vvIBDV is still presenting a serious economic threat to the poultry industry in different areas of Diyala Governorate
(Iraq), in addition to the areas not included in the current study, in which very high mortality was recorded. Therefore, the real -time-PCR technique was used to determine the virulence of the virus that emerged in those fields.

It is well known that the molecular characterization of vvIBDV in diverse regions of the world was very important for understanding the trends in the evolution, spread, and field status of IBDV for effective control of IBD in broiler chickens (Cheggag et al., 2020). In the current study, the genetic characterization of 2 vvIBDV isolates was carried out by sequencing and analysis of the HVR of the VP1 and VP2 genes. The Threshold Cycle (Ct) value for RT-PCR for the isolates (Diyala/VP2/MW883071) collected from bursa tissue ranged from 16.6 to 25.7 indicating that these strains were vvIBDV. The present study was in agreement with those of (Wu et al., 1992; Moody et al., 2000) who reported that conventional RT-PCR has been useful to differentiate IBDV serotypes and subtypes, by using a primer pair that was designed based on the hypervariable region of VP2 genome that can differentiate serotype 1 from serotype 2 . However real-time- RT-PCR methods for diagnosis of IBDV allow rapid IBDV diagnosis and can provide a quantitative measure of the viral load of IBDV. The nucleotide sequence spanning the HVR of the vvIBDV isolated (MW883071) in this study was compared to 31 vvIBDV strains isolated in different countries as a reference of the genome sequences available in NCBI. Generally, the IBDV strains local isolate with known vaccine and field strains are most related to reference isolate named 710-Jordan with accession No. (MF142560.1). Sequence alignment between Diyala local isolate (Diyala/VP2/MW883071) and their corresponding partial VP2 strains from NCBI 710-Jordan (MF142560.1) in one cluster with the group of very virulent IBDV predominantly vvIBDV pathotype or vvIBDV reassortment strains from the USA with similarity amongst them estimated $99.2 \%$ and the same similarity (99.2) with the reference strain 267 Jordan (MF142517.1) VP2 gene as shown in the phylogenetic tree (Figure 3).

Meanwhile, the sequence identity of the partial VP1 gene of the local Diyala isolate (Diyala/VP2/MW883071) is mostly related to isolate 710-Jordan (MF142485.1) from GenBank with sequence similarity reached $99.2 \%$. The identity decreased to reach $98.7 \%$ when compared with the reference 267-Jordan (MF142466.1) from the USA.

The finding of the current study was in concordance with the report of another study by van den Berg et al. 
(2004) and Cheggag et al. (2020) who showed that the molecular characterization of HVR vvIBDV grouped within one of three major genogroups compared with the reference strain sequences retrieved from GenBank from different regions of the world. These genogroups were namely genogroup 1 (predominantly classical), genogroup 2 (predominantly variant), and genogroup 3 . The former was predominantly vvIBDV pathotype or vvIBDV due to reassortment based on the segmented genome source of the virus. The high homology between Diyala local isolate (Diyala/VP2/MW883071) and another vvIBDV isolate from the USA, namely 710-Jordan (MF142560.1), 267 Jordan (MF142517.1), 710-Jordan(MF142485.1), and 267-Jordan(MF142466.1) with the sequence Identity of (99.2, 99.2, 99.2 and 98.7) respectively. The existence of these isolates in Iraq with this identity might be attributed to the fact that such isolates are with international existence (Biswal et al., 2012).

\section{CONCLUSION}

Regarding the obtained results of the present study, it can be concluded that the use of real-time RT-PCR can help greatly in the differentiation of vvIBDV from that of nvIBDV as two samples appeared vvIBDV and two samples appeared nvIBDV out of 4 bursa tissue samples collected from infected broiler chickens. Furthermore, partial sequence of IBDV of local strain with accession number (A2075675.001) showed similarity with 710Jordan isolates with accession number (MF142560.1) and to isolate 267-Jordan (MF 142517.1) with a higher identity reach to $(99.2 \%)$. The present study is one of the first molecular studies on infectious bursal disease virus in this province and the results can attract the attention of researchers for further studies.

\section{DECLARATIONS}

\section{Acknowledgments}

We would like to thank the staff members of the poultry farm (College of the Veterinary Medicine/ University of Diyala-Diyala, Iraq) and the experimental animal hall for their help. We also acknowledge the College of the Veterinary Medicine University of Diyala for logistic supports.

\section{Authors' contribution}

Amer Khazaal A-Azawy and Karim Sadun Al-Ajeeli proposed the hypothesis, designed the study, and conducted the serological and molecular works. Ammar
Taleb Nasser collected samples from poultry farms. All authors contributed to manuscript preparation and approved the final manuscript.

\section{Ethical considerations}

Ethical issues (including plagiarism, consent to publication, misconduct, data fabrication and/or forgery, double publication and/or submission and replication). Exactly done by all authors.

\section{Competing interests}

The authors declare that they have no competing interests.

\section{REFERENCES}

Ali M (2001). Isolation of chicken infectious anemia virus from outbreaks in broilers chickens in Egypt. Journal Egypt of Veterinary Medicine Association, 61: 137-147. DOI: http://www.doi.org/10.5455/javar.2017.d232

Al-Sheikhly F, Mutalib AA, and Rasheed DK (1978). Infectious bursal disease in chickens. 4th annual conference of Iraq Veterinary Medical Association, Baghdad, p. 13

Biswal JK, Sanyal, A, Rodriguez LL, Subramaniam S, ArztJ, Sharma GK, and Dash BB (2012). Foot-and-mouth disease: Global status and Indian perspective. Indian Journal of Animal Science, 82(2): 109-131. DOI: http://www.doi.org/10.3390/vaccines7030090

Cheggag M, Zro K, Terta M, Fellahi S, Mouahid M, El Houadfi M, and Kichou F (2020). Isolation, molecular, and pathological characterization of infectious bursal disease virus among broiler chickens in Morocco. Journal of World Poultry Research, 10(3): 493-506. DOI: http://www.doi.org/10.36380/jwpr.2020.57

Fauquet CM, and Mayo MA (2001). The 7th ICTV Report. Archives of Virology, 146(1): 189-194. Available at: https://link.springer.com/content/pdf/10.1007\%2Fs007050170203.p $\underline{\mathrm{df}}$

Hair-Bejo M, Ng MK, and Ng HY (2004). Day-old vaccination against infectious bursal disease in broiler chickens. International Journal of Poultry Science, 3(2): 124-128. DOI: http://www.doi.org/10.3923/ijps.2004.124.128

Ingrao F, Rauw F, Lambrecht B, van den Berg T (2013). Infectious bursal disease: A complex host-pathogen interaction. Developmental and Comparative Immunology Journals, 41: 429 438. DOI: http://www.doi.org/10.1016/j.dci.2013.03.017

Lukert PD, and Saif YM (2003). Infectious bursal disease. In: Diseases of Poultry. 11th Edition. Iowa State University. Press Ames, pp. 161-180. Available at: https://scirp.org/reference/referencespapers.aspx?referenceid=9224 $\underline{31}$

Mawgod SA, Arafa AS, and Hussein HA (2014). Molecular genotyping of the infectious bursal disease virus (IBDV) isolated from broiler flocks in Egypt. International Journal of Veterinary Science and $\begin{array}{lll}\text { Medicine, } & 2(1) \text { : } & \text { 46-52. }\end{array}$ http://www.doi.org/10.1016/j.ijvsm.2014.02.004

McNulty MS, Connor TJ, McNeilly F, McLoughlin MF, and Kirkpatrick KS (1990). Preliminary characterisation of isolates of chicken anaemia agent from the United Kingdom. Avian Pathology, 19: 6773. DOI: http://www.doi.org//10.1080/03079459008418657.

Meir R, Jackwood DJ, and Weisman Y (2001). Molecular typing of infectious bursal disease virus of Israeli field and vaccine strains by 
the reverse transcription/polymerase chain reaction/restriction fragment length polymorphism assay. Avian Diseases, pp. 223-228. Available at: http://www.jstor.org/stable/1593032

Moody A, Sellers S and Bumstead N (2000). Measuring infectious bursal disease virus RNA in blood by multiplex real-time quantitative RTPCR. Journal Virology Methods, 85: 55-64. DOI: http://www.doi.org/10.1016/s0166-0934(99)00156-1

Muller H, Mundt E, Eterradossi N and Islam MR (2012). Current status of vaccines against infectious bursal disease. Avian Pathology, 41(2): 133-139. DOI: http://www.doi.org/10.1080/03079457.2012.661403

Mwenda R, Changula K, Hang'ombe BM, Chidumayo N, Mangani AS, Kaira T, and Simulundu E (2018). Characterization of field infectious bursal disease viruses in Zambia: Evidence of cocirculation of multiple genotypes with predominance of very virulent strains. Avian Pathology, 47(3): 300-313. DOI: http://www.doi.org/10.1080/03079457.2018.1449941

Saif YM, and Barnes HJ (2003). Diseases of poultry. 11th Edition. Ames, Iowa: Iowa State Press, pp. 1070-1080. DOI: http://www.doi.org/10.1647/10826742(2003)017[0109:BR]2.0.CO;2

Schat KA, and van Santen VL (2013). Chicken Infectious Anemia Virus and Other Circovirus Infections. In Diseases of Poultry, D.E. Swayne (Editor). John Wiley and Sons, Inc. DOI: http://www.doi.org/10.1002/9781119421481.ch8

Sharma JM, Kim IJ, Rautenschlein S, and Yeh HY (2000). Infectious bursal disease virus of chicken: Pathogenesis and immunosuppression. Development Comparative Immunology, 24: 223-235. DOI: http://www.doi.org/10.1016/s0145-305x(99)00074$\underline{9}$
Shehata AA, Sultan H, Halami MY, Talaat S, and Vahlenkamp TW (2017). Molecular characterization of very virulent infectious bursal disease virus strains circulating in Egypt from 2003 to 2014. Archives of virology, 162(12): 3803-3815. DOI: http://www.doi.org/10.1007/s00705-017-3554-3

Sommer F, and Cardona C (2003). Chicken anemia virus in broilers: Dynamics of the infection in two commercial broiler flocks. Avian diseases, 47(4): 1466-1473. DOI: http://www.doi.org/10.1637/7048

Van den Berg TP (2000). Acute infectious bursal disease in poultry: A review. Avian Pathology, 29(1): 175-194. DOI: http://www.doi.org/10.1080/03079450050045431

Van den Berg TP, Morales D, Eterradossi N, Rivallan G, Toquin D, Raue R, Zierenberg K, Zhang MF, Zhu YP, Wang CQ et al. (2004). Assessment of genetic, antigenic and pathotypic criteria for the characterization of IBDV strains. Avian Pathology, 33: 470-476. DOI: http://www.doi.org/10.1080/03079450400003650

World Organization for Animal Health (OIE) (2018). Terrestrial manual: Infectious bursal disease (Gumboro disease). OIE, pp. 931-951. Available at: https://www.oie.int/fileadmin/Home/eng/Health_standards/tahm/3.0 3.12 IBD.pdf

Wu CC, Lin TL, Zhang HG, Davis VS, and Boyle JA (1992). Molecular detection of infectious bursal disease virus by polymerase chain reaction. Avian Diseases, 221-226. DOI: http://www.doi.org/10.2307/1591494

Zanella A, Dall'Ara P, Grilli G, Rampin T, Sironi G, Lavazza A, and Treccani A (2001). Interaction between Marek's disease and chicken infectious anaemia viruses. Selezione Veterinaria (Italy), 10: 727-742. DOI: http://www.doi.org/10.1080/03079459408418994 